\title{
DELITOS FINANCIEROS Y ECONÓMICOS
}

\section{Por: Abog. César Ramos Cáceres}

Profesor Investigador, Instituto de Investigación Jurídica

Universidad Nacional Autónoma de Honduras.E-Mail: cesar_ramos63@yahoo.es

\section{Resumen}

El presente trabajo de investigación nos ha conducido a conocer las situación difícil que actualmente atraviesa nuestro país, a causa de la corrupción imperante de personas encargadas de administrar instituciones con fuertes cantidades de recursos económicos y que su ambición desmedida los ha llevado a la comisión de los denominados delitos económicos y financieros, conocidos comúnmente como "Delitos de Cuello Blanco", por ser éstos cometidos por personajes influyentes de nuestras sociedades.-

Se ha concluido que la falta de rigidez en la aplicabilidad de las leyes existentes que regulan este tipo de situaciones, y por la impunidad casi institucionalizada; este tipo de delitos se ha acrecentado, lo que ha venido también al alza de los índices de pobreza y miseria en nuestras sociedades, por lo que se ha recomendado la implementación de fuertes medidas que contribuyan a hacer eficaz la prevención en la comisión de este tipo de delitos.-

Palabras clave: Delito económico, delito financiero, fraude, lavado de activos, corrupción.

\section{Abstract}

This research paper has led us to understand the difficult situation currently faced by our country, because of the prevailing corruption of people who administer institutions which possess large amounts of economic resources and their ambition has led them to commit the so called economic and financial crimes, commonly known as "white neck crimes", these being committed by influential people in our societies.

It has been concluded that due to the lack of rigidity in the applicability of the novel and few existing laws governing such situations, and due to the almost institutionalized impunity, which has also contributed to the high rates of poverty and misery in our society. Therefore it has been recommended the implementation of strong measures that help to make effective in preventing the commission of such crimes.

Keywords: Economic crime, financial crime, fraud, money laundering, corruption. 


\section{INTRODUCCIÓN}

El presente trabajo de investigación que se expone está referido a una de las situaciones que en los últimos años ha socavado y contribuido en gran medida al resquebrajamiento de la estructura de la economía de nuestro país; como país en vías de desarrollo, pero que según resultados de nuestra investigación, no se escapan de este problema los países de economías y sociedades denominadas sólidas, cual es la comisión de los denominados delitos económicos y financieros.

Por la similitud de su materia o el objeto sobre la que versan y los perjuicios o consecuencias que de estos resultan, se presentan como originados en el ámbito de una actividad económica, razón por la que en este trabajo haremos referencia a los dos tipos de ilícitos conceptuados como Delitos Económicos y Delitos Financieros.

La delincuencia económica - financiera ha merecido en los últimos decenios una atención cada vez mayor por parte de la doctrina científica, pues comparado con otro tipo de delitos ha sido poco el interés que se le ha dado, a ello se debe que muy pocos tratadistas y estudiosos del derecho profundicen sus conocimientos por este tema del delito penal económico y financiero, razón también por la cual en el compendio de materias que se estudian en la formación de profesionales del derecho, al menos en nuestras universidades, casi nada se estudia sobre esta temática; de igual manera se aprecia que en nuestra legislación penal sustantiva vigente, no se tipifica con claridad este tipo de delito, lo que contribuye grandemente a que los que lo cometen queden cobijados por la denominada impunidad, muy de moda en los últimos años en nuestro país, fortalecido por los últimos desafueros económicos suscitados con la quiebra de bancos y otras instituciones financieras las cuales han sido muy sonados y por ende del conocimiento general.

En Honduras se dice, con sobrada razón, que la justicia ha criminalizado la pobreza, puesto que la persecución a actos ilícitos originados en la falta de medios económicos es la que priva, esto se reafirma cuando se realizan los mayores esfuerzos para legislar y combatir otro tipo de delitos que generalmente son cometidos por personas pertenecientes a las clases desposeídas del país, aunque sus daños o efectos sean menores a los causados por los delitos referidos en este trabajo, los cuales son cometidos por miembros de la alta sociedad o personajes influyentes, pues su magnitud radica en que estos delitos de índole económico producen efectos más lesivos debido a su cuantía y al número de personas que resultan afectadas. 
Los sistemas penales evidencian por su parte una distorsión estructural fundamental, solo persiguen con cierto grado de eficiencia, la delincuencia convencional, definiendo como infractor a las personas pertenecientes a clases subalternas.- Esta distorsión estructural fortalece la imagen estereotipada de un delincuente pobre o violento.Como bien lo señala Baratta, partiendo de definición legal, "la criminalidad es un comportamiento que podría atribuirse a sectores privilegiados de la sociedad y no a una minoría estigmatizada y desviada, como se hace tradicionalmente."

Cada vez más frecuentemente, el moderno Derecho Penal tiene que ocuparse de comportamientos delictivos, principalmente de carácter económico, que se cometen normalmente en el seno de grandes empresas, y en los últimos años los delitos de índole económico han ido ganando casta de naturaleza propia y específica, a pesar de que el volumen de obras que se le dedican, no obstante su vertiginoso aumento, sigue siendo pequeño o casi nulo especialmente en los países centroamericanos, en comparación con lo que sucede en otros países de mayor desarrollo económico y social, donde se les ha puesto una mayor atención.-

Hechos o ilícitos de este tipo se han dado y se darán siempre, aunque cada vez con mayor profusión en esta época en la que la globalización y el control de la economía están en manos de algunas pocas empresas multinacionales que dictan sus propias leyes, al margen o incluso claramente en contra de las normas jurídicas que regulan sus actividades, sin que ello plantee ninguna responsabilidad penal para sus dirigentes y las personas físicas que actúan en su nombre y representación.- Detrás de toda esta impunidad hay causas de todo tipo, políticas, económicas, y por supuesto también jurídicas.-Prácticamente, los hechos que se cometen en el ámbito de estas organizaciones quedan al margen del Derecho Penal, y, en todo caso, en los pocos casos en los que se llega a exigir una responsabilidad penal, ésta recae sobre personajes secundarios y nunca sobre los auténticos y verdaderos responsables.

Actualmente parece que hay acuerdo en un importante sector de la doctrina en cuestionar, por lo menos respecto a algunas formas de criminalidad y sobre todo respecto a aquella que se comete en el ámbito de una gran empresa, la idea de que el ejecutor material directo del hecho es el principal responsable del mismo.- Esta idea está enraizada en la imagen del autor de los delitos tradicionales contra la vida, la libertad sexual o la propiedad, que son los delitos sobre los que se ha elaborado la teoría general del delito. 
En los últimos años, la visibilidad y la intensidad del delito financiero-económico y la manipulación de mercados han aumentado significativamente en el ámbito nacional e internacional, de los cuales se hará referencia en el desarrollo de la temática en el presente trabajo.- En el campo transnacional el suceso del once de septiembre del dos mil uno, también dio lugar a cuestiones muy serias acerca del uso de los mercados financieros internacionales para financiar el terrorismo.- Los fracasos corporativos importantes están vinculados con fraudes financieros y el delito económico y la manipulación de mercados en jurisdicciones poco reguladas y poco dispuestas a colaborar como la nuestra, siguen siendo problemas importantes para los defraudadores al permitirles la libertad absoluta como si lo que hicieron fuese un delito de menor cuantía o comúnmente Ilamado de "bagatela".- Situaciones similares han ocurrido en otros países, con la diferencia que en ellos, los tribunales no han tenido compasión con los actores responsables del fraude o delito y por ello son remitidos a las prisiones, lo que hasta la fecha no ha ocurrido en Honduras, ni existen indicios que a corto plazo suceda. 


\section{I.- CONCEPTUALIZACIÓN}

Resulta indispensable precisar lo que se ha entendido por delito contra el orden económico o delito económico y financiero, y con la mayor claridad para nuestro presente trabajo, es preciso conceptuar lo que es el delito económico; siendo los que su comisión lesionan el orden económico social y por ello son reconocidos como delitos económicos o financieros según el caso; diferenciándose únicamente su terminología en que el delito financiero es el cometido por personas que dirigen las instituciones financieras (bancos, bolsa de valores, financieras, cooperativas, etc.) Como es lógico, como en la diversidad de materias existen varios autores que han hecho sus propias definiciones sobre estos delitos, para el caso Rafael Miranda Gallino en una de sus obras sobre el tema define el delito económico en los siguientes términos: "es la conducta punible que produce una ruptura en el equilibrio que debe existir para el normal desarrollo de las etapas del hecho económico; o bien, la conducta punible que atenta contra la integridad de las relaciones económicas públicas, privadas o mixtas, y que, como consecuencia, ocasionan daño al orden que rige la actividad económica o provoca una situación de la que puede surgir este daño". ${ }^{1}$ El profesor Miguel Bajo Fernández, quien ha dedicado espaciosos estudios a este tema, al punto que fue quien originalmente redactó gran parte de las figuras que integraron el proyecto del Código Penal Español de 1989, advierte que con este tipo de delitos existen dos criterios a saber, uno de orden económico social amplio y otro restringido.- Ha dicho el profesor de la Universidad Autónoma de Madrid, España, "A mi juicio, el orden económico social puede ser entendido de dos formas. En un sentido estricto, orden económico social se entendería como "regulación jurídica del intervencionismo estatal en la economía de un país". Al tenor de este concepto estricto, los delitos económicos quedarían reducidos a aquellos que atentan contra la determinación o formación de los precios, los delitos relativos a divisas y medios de pagos internacionales, las infracciones de contrabando y el delito fiscal.- Esta concepción estricta reduce excesivamente el contenido del derecho penal económico. Existe, sin embargo, una concepción amplia del orden económico que lo identifica con "la regulación jurídica de la producción, distribución y consumo de bienes y servicios". Al tenor de esta concepción podríamos incluir aquellas figuras delictivas que, aunque lesionan directamente bienes jurídicos de carácter individual (propiedad, posesión, derecho de crédito, patrimonios, etc) afectan gravemente también el orden económico entendido en el sentido expuesto, podrían incluirse aquí los delitos de insolvencia, competencia ilícita, abusos de créditos, estafa, fraudes ali-

${ }_{1}^{1}$ Miranda Gallino, Rafael.- Delitos contra el orden económico.,- Editorial Pannedille 1970. Pag. 17 
mentarios, delitos laborales, delitos relacionados con la actividad de las sociedades mercantiles, etc.

En la obra "Derecho Penal Económico Aplicado a la Actividad Empresarial", se define este tipo de delitos, así: "Delito económico en sentido estricto, es la infracción jurídica-penal que lesiona o pone en peligro el orden económico entendido como regulación jurídica del intervencionismo estatal en la economía de un país.- Y delito económico en sentido amplio es aquella infracción que, afectando un bien jurídico patrimonial individual, lesiona o pone en peligro, en segundo término, la regulación jurídica de la producción, distribución y consumo de bienes y servicios". ${ }^{2}$

Rafael Bielsa, citado por Miranda Gallino, ha dicho sobre ellos: "Son delitos de gente inteligente avanzada en los negocios, conocedora de las leyes y reglamentos y de las artimañas para eludir sanciones, influyente por su poder corruptor, y que tiene relaciones mundanas y políticas con los funcionarios" ${ }^{3}{ }^{3}$

García Pablos de Molina, cuyos conceptos sobre el tema han sido recogidos por el autor argentino Fernando Horacio Molinas en su obra "Delitos de Cuello Blanco en la Argentina", ha concluido que el delito económico es, "aparentemente, una operación financiera o mercantil, una práctica o procedimiento como otros muchos en el complejo mundo de los negocios.- La actividad no es en sí misma llamativa, repugnante como lo es, en forma inequívoca y obvia, un homicidio o unas lesiones; es neutra y aparentemente lícita.- La ilicitud no se constata directamente, porque es necesario evaluarla de su confrontación con la norma; normas, por otra parte, complejas, muy técnicas, incomprensibles para el no experto, y previo los oportunos dictámenes periciales.- El Corpus delictivo a menudo una cifra, un guarismo, un acuerdo colegiado nunca produce el rechazo y la desaprobación inmediata del delito convencional.- El negocio criminal se inserta en los procesos normales del trabajo jurídico mercantil.Aprovechar la complejidad y tecnificación de éste, para no despertar sospechas.- Es bien difícil distinguir un buen negocio de una colosal estafa". ${ }^{4}$

El profesor español César Herrero Herrero, en su obra "Los Delitos Económicos", aparecida en 1992, sostiene que las normas del derecho penal económico surgen en los Estados modernos, únicamente, para preservar las condiciones indispensables para el mantenimiento del ordenamiento jurídico económico. Así, asume el criterio de J.A. Martos Núñez, según el cual, el derecho económico es "El conjunto de nor-

2 Bajo Fernández, Miguel.- Derecho Penal Económico Aplicado a la Actividad Empresarial .- Ed. Civitas, Madrid, 1978; P. 42 y 43

3 Miranda Gallino, Rafael.- Ob. Cit. P.17

${ }^{4}$ Molinas, Fernando Horacio.- Delitos de Cuello Blanco en la Argentina 1989. pag.22 
mas jurídico-penales que protegen el sistema económico constitucional". Continúa manifestando el referido autor que "Por sistema económico constitucional ha de entenderse el conjunto de instituciones y mecanismos de producción, distribución, consumo y conservación de bienes y servicios que fundamentan el orden socio-económico justo, objetivo esencial del Estado social y democrático de Derecho". Bajo estos parámetros, Herrero Herrero, concluye que: "Entonces, considerando estas premisas puede decirse que habrá delito económico cuando se da una conducta (o comportamiento) típica, antijurídica, imputable, culpable y punible, a la luz de una ley perteneciente al Derecho económico". ${ }^{5}$

Juan Antonio Martos Núñez, profesor de derecho penal de la Universidad de Sevilla, en su interesante obra, Derecho Penal Económico, después de efectuar un detenido estudio de los aspectos constitucionales del derecho penal económico de su país y siguiendo de cerca el concepto de delito de cuello blanco, acuñado por el sociólogo norteamericano Edwin Sutherland, ha concluido que delito económico es: "La acción realizada por personas respetables de elevada posición socio-económicos, en el desempeño de su profesión y con abuso de poder, que lesiona o pone en peligro manifiesto y grave el orden público económico". ${ }^{6}$

El Maestro colombiano Luis Romero Soto, enseña como el Estado ha abandonado su papel de espectador para asumir un rol de actor y director de los cambios económicos manifestándose en dos formas principales: "La de 'intervención”, es decir, las de dirigir las diversas políticas (de crédito, de control de precios, etc), y la de 'protección' que, como su nombre lo indica, tiene como objeto amparar a la parte más débil de la sociedad: comunicadores, contratantes.

La expresión delito económico incluye tres clases de infracciones, empezando por los delitos patrimoniales comunes, siguiendo aquellos que lesionan en cualquier forma, actividades de intervención y protección estatales, de que se ha hecho mención antes y, por último, todas las infracciones que vulneran bienes jurídicos colectivos. ${ }^{7}$ A su vez, el profesor Luis Carlos Pérez, con un criterio más social sobre estos ilícitos, precisa: "Ios delitos contra el orden económico social, son violaciones del derecho que asiste a las comunidades humanas, sin distinción de clases, para beneficiarse con

5 Herrero Herrero, Cesar.- Los Delitos Económicos, Perspectiva Jurídica y Criminológica, Ministerio del Interior, Secretaría General Técnica, Madrid, 992.p. 38 y ss

6 Martos Núñez, Juan Antonio, Derecho Penal Económico. Editorial Montecorvo, S.A., Madrid, 1987. p. 160 y ss. 7 Romero Soto, Luis Enrique. Los Delitos Contra el Orden Económico-Social desde el punto de vista del derecho Comparado, publicado en "Revista Cambio Jurídico". Universidad de Los Andes. Cijus.- 1888, p.42. 
los recursos de la naturaleza y los bienes creados por el trabajo en todas sus aplicaciones, así como los rendimientos del dinero y el manejo de este en las empresas, bancos, financieras y demás establecimientos de crédito, realizadas para destruir estos bienes, disminuirlos, distraerlos o aprovecharse ilícitamente de ellos, mediante la violencia y el fraude". ${ }^{8}$

Siempre enfatizando en que el delito económico y financiero en nuestras sociedades, es un delito clasista, la delincuencia económica podemos definirla como aquellas infracciones cometidas por personas de nivel socioeconómico elevado, que actuando en el ejercicio de su actividad profesional y mediante el abuso de confianza inherente al desempeño de su cargo o a las relaciones sociales, lesionan o ponen en peligro el orden económico; esto en relación estrecha con los acontecimientos punibles de índole económica que últimamente se han suscitado en nuestro país.

El derecho penal económico es, sin duda, una parte muy importante del moderno derecho penal y quizás una de las que tengan más futuro, pero todavía falta una elaboración doctrinal capaz de decir con certeza cuál es la extensión, contenido y limites que debe tener este sector del derecho penal. "Y es, por eso, preocupante que se quiera ya dar por supuesto y resuelto con la normativa jurídica que se proyecte un problema que tiene sus raíces fuera del derecho penal y que por lo tanto, mal se puede resolver solo con el derecho penal, si este no va acompañado de reformas más radicales y urgentes de la realidad social, política y económica". ${ }^{9}$

Es de importancia manifestar en este apartado que hay delitos de fraude económico y corrupción en una inacabable variedad de modalidades, inaccesibles en su totalidad: evasión de capitales, ocultación de beneficios, simulación de balances, concesión de monopolios ilegítimos, fraudes con la importación y exportación de mercaderías, en los planes de urbanización y obras de interés general, especulaciones prohibidas, transferencia de bienes de existencia ilegal, exorbitantes negocios con moneda extranjera, bancos internacionales que ofrecen créditos y otorgan "comisiones" con miras a considerables ganancias, uso en propio provecho de subsidios públicos, negocios con licitaciones de empresas públicas y privadas, fraudes administrativos con bienes raíces, creación de sociedades con el propósito de encubrir ciertas maniobras ficticias, insolvencias fraudulentas, contrabandos e infracciones aduaneras, manipulaciones excesivas de los mercados de valores y bursátiles, y otros.-

8 Pérez, Luis Carlos, Tratado de Derecho Penal, parte especial.- Editorial Temis. T.IV. 1985, p.147.

Muñoz Conde, Francisco. La Ideología de los Delitos contra el Orden Socio-económico en el Proyecto de Ley orgánica 9 del Código Penal.- Publicado en: Revista del Código de Abogados Penalistas del Valle.- 1. Primer Semestre de 1987, p.36ss 
Creemos finalmente, que toda conducta que vulnere o ponga en peligro la intervención del Estado en la economía, trátese de una función de dirección o protección se erige un delito económico al igual que los comportamientos mediante los cuales se impide u obstaculiza a los ciudadanos la cabal utilización de los bienes y servicios a que tiene derecho.

\section{II.- CARACTERÍSTICAS ESPECIALES DE LOS DELITOS DE ORDEN ECONÓMICO Y FINANCIERO}

La delincuencia de índole económico y financiera, como ya se ha mencionado, es la que se desenvuelve en el ámbito del movimiento comercial, mediante operaciones ejecutadas y en las que intervienen personas naturales, empresas comerciales, industriales y las denominadas instituciones financieras.Este tipo de sujetos que en sí no aparentan presentar características sociológicas determinadas, generalmente pertenecen a las altas sociedades, por lo que en el ámbito delincuencial se les denomina comúnmente "delitos de cuello blanco".

El norteamericano Sutherland definió este tipo de delincuencia de cuello blanco como la violación de la ley penal por parte de una persona de alto nivel socioeonómico en el desarrollo de una actividad profesional. ${ }^{10}$

Comúnmente el infractor de este tipo de delincuencia es un "personaje respetable" o bien de un nivel socio-económico elevado, lo que le permite ejercer, con mayor o menor éxito, suficiente influencia para impedir la intervención de la víctima o del aparato de persecución estatal; aunque el estatus económico elevado es una característica que ha sido objetada por algunos autores, pues le dan preponderancia al procedimiento ingenioso que utiliza el delincuente de cuello blanco restándole importancia a su nivel socio-económico; sin embargo, es un indicador del que no puede prescindirse, ya que en la práctica, tiene una importante influencia.

También es una delincuencia ligada a una actividad profesional, lo que incluiría la delincuencia de "cuello azul", cuyos autores no siempre pertenecen a los estratos sociales privilegiados. Dentro de estas actividades delictivas podemos mencionar, entre otros, la de los profesionales liberales, como los médicos cuando suministran, ilícitamente, drogas o practican abortos, lo mismo ocurre con el asesoramiento que prestan los abogados en la ejecución de acciones ilícitas o delictivas. De igual forma se incluyen las acciones fraudulentas ejecutadas por los profesionales obreros, espe-

10 Supra Nota 2, p. 27 y 28 Citando la obra de Sutherland. White Collar Crime. New York. Ed. De 1961 p.9 
cialmente en la construcción de viviendas, carreteras, reparación de autos, electrodomésticos, etc.- Se podría hablar en este caso de un delito ocupacional, en lugar del delito de cuello blanco y que sería el que se comete en el ejercicio de una profesión civil o en estrecha relación con ella, tal como ocurre, con las actividades recién citadas y también con los delitos cometidos por las grandes corporaciones, las prácticas desleales de los comerciantes, así como la corrupción de funcionarios.

Por otro lado, desde el punto de vista del objeto, también abarcaría la adulteración de alimentos y bebidas, los delitos fiscales, aduaneros y monetarios. En realidad, el delito ocupacional se integra dentro de la criminalidad económica, tal como la definió el mismo Sutherland, pues al fin y al cabo son actividades profesionales mercantiles en las que se realizan actos criminales o ilícitos. ${ }^{11}$

Desde el punto de vista criminológico, la delincuencia económica se define como las infracciones lesivas del orden económico cometidas por personas pertenecientes a estratos altos en el ejercicio de su actividad profesional. ${ }^{12}$

La trascendencia social de esta delincuencia se manifiesta, en primer término, por la cuantía de los daños ocasionales y en segundo lugar, por el reclutamiento del autor entre los miembros de la alta sociedad.- En muchas ocasiones, por el poder político o económico que ejerce, el delincuente de cuello blanco, logra que terceros o subalternos sean los autores materiales del hecho delictivo, lo que dificulta, sin duda alguna, la persecución del autor que realmente ha dominado la acción.-

Según Sutherland y Cressey, las características del delito de cuello blanco (económico-financiero), son las siguientes:

1. Comisión de un delito

2. Pertenencia del autor al estatus social elevado

3. Comisión de la infracción en el ejercicio de una actividad profesional o lo que se denomina "delincuencia de caballeros"

4. El sujeto de delito es una "persona respetable"

5. Existe abuso de confianza

6. La infracción debe ser apta para lesionar o poner en peligro el orden económico.

11 Cruz Castro, Fernando.- “Discriminación e Ineficiencia en la persecución del Delito Económico”. La Inevitable

Perversión del Sistema Penal. 2000. p. 87

12 Fernández, Miguel: “Derecho Penal Económico” Ed. Civitad. 1978 p. 49 
7. Existe un abuso de la conciencia social que se estima necesaria para la vida económica, y;

8. Comportamiento abusivo frente a la ignorancia o ingenuidad de la víctima.

\section{III.- LOS GRAVES PERJUICIOS OCASIONADOS POR LA DELINCUENCIA ECONÓMICA Y FINANCIERA.}

\section{A.- LOS DAÑOS ECONÓMICOS.- ALGUNAS CIFRAS.}

La indulgencia, la tolerancia y el disimulo con que se ha tratado en Honduras a los delincuentes que cometen delitos económicos-financieros, comúnmente denominados de "cuello blanco", son factores que han influido en los órganos del Estado relacionados con la prevención, regulación y control de los mismos; a no visualizar y menos a sancionar, los graves perjuicios ocasionados a los sectores más vulnerables de la población y a la economía del país en general.-

El perjuicio económico provocado por este tipo de delincuencia en Honduras y en gran número de países del globo terráqueo es cuantioso.

En la economía globalizada mundial la delincuencia organizada genera grandes sumas de dinero mediante el tráfico de drogas, trata de blancas, prostitución, el contrabando de mercaderías, la evasión fiscal, el fraude, la malversación, la quiebra de bancos y otros delitos financieros.

Sin retrotraernos mucho en el tiempo, durante los últimos años múltiples escándalos han sacudido el mundo financiero en todos los confines de la tierra. A manera de ejemplo podemos señalar los siguientes casos, que han sido titulares en diferentes medios de prensa en el mundo, para el caso en Alemania, el Presidente del Deutche Bank, el Presidente de la Operadora de Telefonía MANNESMANN y el dirigente del Sindicato I.G.METALL, fueron acusados por la fiscalía alemana de haber cometido fraude durante la operación de venta de la Compañía germana en el Grupo Británico VODAFONE.- De acuerdo con el informe de la fiscalía, los acusados provocaron daños por valor de entre 39 y 76 millones de euros, por la aprobación y recepción de indemnización y premios por un importe total de 25.5 millones en el proceso de adquisición de MANNESMANN por la citada operadora británica. Según los especialistas, este proceso ha tenido significativas repercusiones en los medios de comunicación y perjudicó el valor de las acciones del Deutsche Bank, el primer banco alemán en la bolsa.

En Alemania se ha considerado que el valor de los daños ocasionados por la de- 
lincuencia económica se puede estimar en unos diez mil o quince mil millones de marcos por año.

En uno de los países más ricos y organizados del mundo, los Estado Unidos de Norte América, este tipo de delincuencia económica no escapa, y como ejemplo citaremos que hace unos pocos años, la Comisión Federal de Valores de Estados Unidos y el fiscal general del Estado de Nueva York refirieron que diez de los mayores y prestigiosos bancos de inversión de Wall Street pagaron multas de 1,400 millones de dólares para resolver acusaciones de fraude, mediante acuerdo extrajudicial, para tratar de compensar a los inversionistas perjudicados por ellos.

También en Gran Bretaña se descubrió que 15 bancos que operaban en ese país tenían "importantes debilidades en sus controles de lavado de dinero".- Por un informe de la Autoridad de Servicios Financieros de ese país (FSA) se afirmaba que esos bancos habían permitido que unos 1,300 millones de US\$ pasaran a través de cuentas vinculadas al antiguo gobernador militar de Nigeria.

En ese mismo sentido se involucraron, según la Comisión Federal de Bancos Suizos, por haber cometido "deslices organizativos" con el dinero del propio ex gobernante militar de Nigeria, bancos de la magnitud del Credit Suisse Private Bancking, Bank Hoffmann, Bank Lew, Credita Suisse, USP UNION Bacaria Privada, y otros. ${ }^{13}$

En el ámbito latinoamericano algunos casos de delitos financieros los ejemplificamos, cuando en 1982 el sistema financiero colombiano sufrió uno de los mayores descalabros de que se tenga noticia en su historia, como consecuencia de múltiples factores, que se venían confabulando contra su ordenamiento bancario, tales como problemas en materia de control, concentración de operaciones de créditos y depósitos en pocas manos y en ocasiones, la falta de seriedad en su manejo, esa crisis causó tanto daño a su economía y a incontables ciudadanos, lo que obligó a su gobierno de turno a dictar un decreto que buscó asegurar la confianza del público en el sector financiero colombiano. ${ }^{14}$

El colofón de esta relación de hechos delictivos lo tenemos en el caso denunciado por el Banco Central de la República Dominicana, cuando se comprobó que el in-

13 Revista CCC Delito Financiero Internacional -

14 Quintero Hernández, Hernando.- Los Delitos en el Estatuto Orgánico del Sistema Financiero. Pag. 126. 
tervenido Banco Intercontinental, S.A. efectuó operaciones fraudulentas o irregulares por más de 55.000 millones de pesos, aproximadamente unos 2,000 millones de dólares.

El Banco Central Dominicano, intervino El BANINTER, a causa de problemas financieros que el mismo confrontaba. En el transcurso de la investigación se comprobaron gastos excesivos de los principales ejecutivos del banco, cuyo presidente y principal accionista era un empresario financiero, entre cuyos negocios, relacionados con el Banco Intercontinental, S.A., se encuentran 4 periódicos, más de 70 emisoras de radio, canales de televisión y una empresa de televisión por cable.- También se detectaron alteraciones fraudulentas en la contabilidad de activos estimados en unos 670 millones de dólares y la compra de empresas improductivas y mal administradas.

El sistema político norteamericano también ha sido alterado por el dinero, y el hecho de que sea mayoritariamente legal no lo hace menos corrupto.- De igual manera por cuestiones ilícitas de índole económico gobiernos de Europa y Japón se han venido abajo por culpa de los pactos ilegales entre altos funcionarios y firmas de grandes emporios económicos. ${ }^{15}$

Como puede apreciarse, las naciones económicamente ricas no escapan a la corrupción y es quizá, también cierto, que los gobiernos grandes tienden a ser menos corruptos; contrario a ello según resultados obtenidos por las encuestas que las naciones más corruptas son, de hecho, las más pobres y consecuentemente son los Estados más débiles los que carecen de mecanismos de lucha contra la corrupción, como veremos más adelante lo que sucede en nuestro país.

En Honduras, en todo tiempo se han realizado delitos de índole económico-financieros; pero en la década de los noventa cobró ímpetu adicional el principio del enriquecimiento rápido, con el menor esfuerzo y en el menor tiempo posible, a expensas de todo principio ético, sin tener en cuenta una manera legal y moral; esto a niveles gubernamentales y no gubernamentales.

Los problemas de corrupción en el sistema financiero nacional, con mayor énfasis tiene como escenario el sistema bancario, después que en la década de los setenta se tiene conocimiento de la quiebra del primer banco, BANFINAN (Banco Financiera

15 Revista Summa.- Tina Rosemberg.- Pag. 9 edición octubre 2002 
Hondureña) y por ello no ameritó siquiera emplazar a los responsables, simplemente porque se demostró que dicho banco tenía suficientes recursos con que responder.

Después de ese caso los quiebra instituciones nuevamente comenzaron a finales de la década anterior, precisamente en el año mil novecientos noventa y nueve, cuando seis financieras y veinte puestos de bolsas de valores se declararon en quiebra.Posteriormente el caso que desata la crisis es el del BANCORP (Banco Corporativo) cuando la Comisión Nacional de Bancos y Seguros, se da cuenta que en ese banco existen graves irregularidades y el 7 de septiembre de 1999 decreta una intervención forzosa, ese mismo año también se decretó la liquidación forzosa de varias financieras, a saber: INTERFINSA, INVERFIN, INVIERTA Y FIRESA, las que operaban en la ciudad de San Pedro sula, Cortés, así como las siguientes empresas que transaban en puestos de bolsas: C\&B Renta a Car, Siga Computación, Central Automotriz, TecnoAuto, Distribuidora de Servicios Generales y Crédito Prendario Hondureño.

Posteriormente también por irregularidades cometidas por sus socios, son intervenidos por la Comisión Nacional de Bancas y Seguros, y pasan al estatus de quebrados, varios bancos y aseguradoras, entre ellas; Banco Hondureño de Crédito y Servicios (BANHCRESER) y varias empresas relacionadas (AHCRESER, CRECER VISA y ANCRES), y por último Seguros Capital, Banco Capital, S.A. y Banco SOGERIN que fue intervenido el 17 de mayo del 2002 por iliquidez, pero solventó su situación al vender sus acciones a BANPAIS. En todos estos casos ha habido malos manejos comprobados, no solo por administraciones inadecuadas, sino por abusos cometidos directamente por accionistas metidos a administrar estas empresas bancarias y financieras, pero sobre los culpables no se ha interpuesto ninguna acción legal.

Las consecuencias obtenidas de la comisión de esas infracciones económicas, arrojan cifras muy escalofriantes en detrimento de la economía del país; según un informe del Consejo Nacional Anticorrupción, señala que el costo financiero de los procesos de liquidación ha alcanzado 4,204.3 millones de lempiras, de los que 2,754.7 miIlones fueron absorbidos por el gobierno, 450 millones fueron cargados al Banco Central de Honduras y 999.6 millones al Fondo de Seguros de Depósitos (FOSEDE). Estas cifras Cubiertas por el Estado de Honduras y que es equivalente al $5 \%$ del P.I.B., y que se detallan a continuación: 


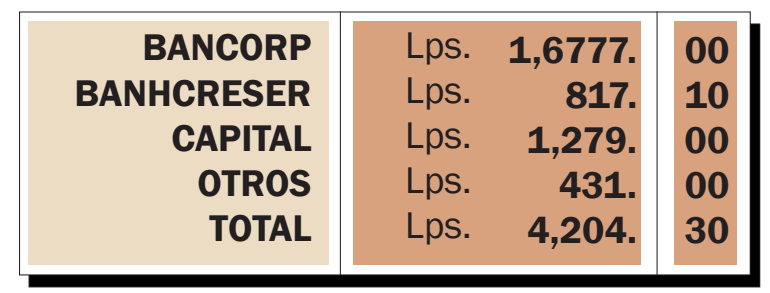

Ese monto se desprende de información proporcionada por el Comisión Nacional de Bancos y Seguros, donde se ha dejado al descubierto los incumplimientos y violaciones de normas de distinta índole, así como las fallas de tipo administrativo en que a lo largo de un período de varios años incurrieron los socios y administradores de las instituciones bancarias y financieras que fueron declaradas en proceso de liquidación forzosa.

Es lastimoso conocer que "pequeños y medianos ahorrantes depositaron su confianza y sus fondos a "damas y caballeros" que reclamaban ser banqueros, empresarios y asesores financieros innovadores.- El señuelo fue la promesa de pagar tasas de interés elevados, por encima del promedio local, anzuelo propicio para la comisión de actos delictivos que, hasta el presente, los estafadores no hayan sido sancionados con el rigor de la ley". ${ }^{16}$

Para la persecución de los responsables de la comisión de este tipo de ilícitos, los perjudicados y la sociedad en general han tenido un sin número de frustraciones; pues se han obtenido resultados "bastante pobres" con la acción penal efectuada por el Ministerio Público como órgano encargado de perseguir este tipo de delitos; aunado porque el Código Penal nuestro, casi no hace referencia a este tipo de delitos de tipo financiero y económico, no existe una política criminal al respecto y por tibias determinaciones de los jueces, hacen que se conviertan en un mejor disuasivo para que la comisión de esos delitos vuelvan a ocurrir, y como consecuencia lógica, provocando un fortalecimiento a la impunidad.

En otros países, en donde no está tan marcada la corrupción, existe algo que en Honduras soñamos: una justicia que funcione, mecanismos de control estrictos y un proceso que hace que cada escándalo tenga su desenlace final. Allí, el ciudadano es informado, el delito penalizado y el escándalo resulta altamente demostrativo, tanto que aleja de la tentación a todos los que quieran imitar la proeza del "corrupto

16 Argueta Mario R.- El Heraldo, 15 de agosto del 2002 
del momento".- En esos países se sabe que la sobrevivencia del sistema depende de la credibilidad que tenga, y están tratando de llegar al fondo para castigar a los estafadores de altos quilates, a sus cómplices y padrinos políticos, tanto que existen fuertes presiones para que prevalezca la transparencia.

La historia financiera hondureña es triste y oscura, porque sabiendo quienes han sido los responsables de haber llevado a la quiebra a las entidades bancarias y financieras, y últimamente de previsión social, ninguno de nuestros mecanismos es capaz de sentarlos en el banquillo, no hay capacidad para deducir responsabilidades por la calidad de justicia y legislación que tenemos, por lo que nuestra historia financiera está plasmada de impunidad, tanto la Comisión de Banca y Seguros, como los órganos jurisdiccionales han sido fuertemente cuestionados por algunos sectores de la sociedad por su "parsimonia" en la ejecución de procedimientos y deducción de responsabilidad ante los denominados "quiebra bancos" y delincuentes de coello blanco. ${ }^{17}$

Múltiples medidas se toman en el mundo por parte de autoridades supervisoras, organismos internacionales y otras instituciones para luchar contra estos flagelos, como resultados del conocimiento que se tiene de que los daños ocasionados por la criminalidad económica superan la totalidad de los ocasionados por el resto de la delincuencia. $^{18}$

Las cifras económicas que benefician a los infractores, que se aprecian a consecuencia de la comisión de los delitos económicos-financieros son altísimos; sin embargo, la proporción de recursos estatales de todos los países, dedicados al combate del delito convencional y del crimen organizado, siguen siendo escasos, y con mayor razón en los países sub-desarrollados, por tener presupuesto bajísimos, incluso para necesidades generales de la población.- Sobre este punto el sistema político asume una posición convenientemente contradictoria, ya que se pregona la necesidad de perseguir por igual la delincuencia convencional y la no convencional, pero a los órganos de persecución y al poder judicial no se les brinda la independencia y los recursos materiales que requieren para poder desarrollar una acción eficaz frente a la delincuencia económica; agravado esto, que estructuralmente, ni el sistema judicial, ni la policía, están diseñados para perseguir o investigar a los grupos que ostentan el

\footnotetext{
17 Hablemos Claro Financiera .- Edición 13 año 2002

18 Pearce, Frank. “Los Crímenes de los Poderosos” Ed. Siglo XXI- México. 1980. p.106
} 
poder político y económico, y los cuales son los que cometen este tipo de ilícitos.

\section{B.- PERJUICIOS COLATERALES INTANGIBLES.}

Los perjuicios inmateriales provocados por la delincuencia económica se determinan en que se desvían los recursos que el Estado ha presupuestado para la realización de obras sociales en beneficio de la población, en la pérdida de confianza en el tráfico mercantil, las deformaciones en el equilibrio de los mercados y la grave distorsión o eliminación de la competencia. Estos efectos no se pueden determinar de inmediato, sino que se producen a corto o mediano plazo. Sin duda alguna, quien se beneficia con las ganancias ilícitas provenientes de las maniobras fraudulentas con las que los delincuentes económicos y financieros evaden impuestos y otros controles estatales, obtienen una posición ventajosa respecto a otros agentes económicos o frente al mismo consumidor, lo que le podría permitir, dependiendo de la magnitud del ilícito penal, alcanzar posiciones ventajosas en el status en que se desenvuelve, eliminar la competencia e incluso lograr el control monopólico del mercado.

El delito económico también provoca una reacción en cadena, ya que multiplica el número de víctimas. Los perjuicios se transmiten de un sujeto a otro, ocasionando dificultades de pago, crisis y quiebras de las instituciones y empresas, despidos masivos de trabajadores, alza en el tipo de interés, trastornos sicológicos y hasta muertes, agravándose esta cadena de víctimas y perjuicios en los períodos de recesión económica. ${ }^{19}$

Finalmente el fortalecimiento y profundización de la corrupción en la Administración Pública y en instituciones no gubernamentales, en este tipo de delitos casi siempre requiere de un aval, la protección de participación, por omisión u acción, de algún funcionario público del Estado.- "Dentro del efecto corruptor debe destacarse la financiación clandestina e ilegítima de los partidos políticos, ya que dentro del crimen organizado, como los narcotraficantes o las empresas que desarrollan una actividad sistemática de violación al ordenamiento jurídico económico, obtienen importantes "benéficos" al neutralizar la acción estatal mediante la financiación de las campañas políticas de los partidos mayoritarios".- Esta financiación clandestina o ilegal, le asegura al "generoso contribuyente", una poderosa influencia política con la que neutra-

19 Cruz Castro, Fernando.- “Discriminación e Ineficiencia en la persecución del Delito Económico”. La Inevitable Perversión del Sistema Penal. 2000. 
liza la acción estatal.- En estos casos, la generosa contribución a la campaña política se "retribuye" con el "trato privilegiado" que el partido le brinda, desde el aparato de poder político, al delincuente económico que ha asegurado su inmunidad mediante una generosa contribución en la campaña. ${ }^{20}$

De estos acotamientos fácilmente se puede deducir por qué en nuestros países existe una frágil legislación o casi nula para paralizar este tipo de ilícitos, pues personajes de las clases poderosas son los que conforman las estructuras políticas de mando en el país, los que deciden, y ellos no son capaces de legislar en perjuicio de ellos mismos y de sus propios intereses, de ahí el fortalecimiento de la impunidad y del resquebrajamiento económico del país a consecuencia del abuso de poder y la corrupción.

\section{IV.- LEGISLACIÓN HONDUREÑA E INSTITUCIONES AFINES A LOS DENOMINADOS DELITOS ECONOMICOS Y FINANCIEROS.}

Según manifestaciones de los fiscales de la Unidad del Delito Financiero, dependencia de la Fiscalía Especial Contra la Corrupción del Ministerio Público, en Honduras no ha existido una normatividad penal aplicable para las personas que cometen el tipo de delito económico - financiero, como ya manifestamos son los personajes pertenecientes a clase sociales pudientes y gobernantes, consecuentemente resultaría imposible que quienes deciden el rumbo del país, legislen en contra de sus propios intereses y emitan y aprueben leyes que posteriormente les vengan a ser aplicables penalizando sus actos ilícitos, cometidos en el proceso de administración de las empresas e instituciones creadas y dirigidas por ellos mismos.

Es a inicios de la década de los noventa, especialmente en el gobierno de Rafael Leonardo Callejas, la época en que se propició la creación de instituciones de rubros financieros, como campos propicios para duplicar fondos a través de bancos, financieras, aseguradoras, casas de cambio, cajas de ahorro y crédito rural y otros; y lo hicieron sin ninguna regulación, sin ningún marco jurídico que los normara adecuadamente, lo que más tarde vino a propiciar la comisión de delitos financieros y económicos, creando un fuerte impacto en la deteriorada economía nacional.-

20 Cruz Castro, Fernando.- “Discriminación e Ineficiencia en la persecución del Delito Económico”. La Inevitable Perversión del Sistema Penal. 2000. 
Lo parco de las leyes vigentes en Honduras, no permiten enjuiciar a los que cometen este tipo de delitos, es muy poco lo que se hace por combatir a este tipo de delincuentes que hemos denominado de "cuello blanco" y sí considero paradójicamente, que ha sido más fuerte el juzgamiento que de ellos ha hecho la opinión pública a través de los medios de comunicación social del país.

Frecuentemente, se observa en este tipo de imputados una duplicidad ética que les permite, por una parte ser delincuentes y por otra aparecer como ciudadanos perfectamente integrados a la sociedad como miembros de prestigiadas instituciones, clubes, organizaciones empresariales, etc.

Después que se propició la creación desmedida de instituciones financieras, es a partir de 1995 que se empezó a hacer algunas regulaciones necesarias sobre lo que es el Sistema Financiero Nacional; creándose leyes afines, tales como la Ley de Instituciones del Sistema Financiero, mediante decreto ley número 170-95, la cual reconoce los delitos de fraude y estafa, siendo estos delitos los únicos que se tipifican en el Código Penal hondureño; Ley de la Comisión Nacional de Bancos y Seguros, mediante decreto 155-95, la cual le da la potestad a esta comisión para la investigación de los delitos cometidos en instituciones financieras y bancarias; la ley de Seguros de Depósitos en Instituciones del Sistema Financiero, decreto número 53-2001, Ley Temporal de Estabilización Financiera, emitido en 1999, para garantizar un mayor control y supervisión del Sistema Financiero y del mercado bursátil; se creó el Consejo Nacional Anticorrupción mediante Decreto Ejecutivo número 015-2001, cuyo propósito fundamental es proporcionar los instrumentos de las políticas públicas que establezcan las bases institucionales necesarias para combatir la corrupción en todos los niveles de la sociedad hondureña; y una de las últimas leyes que se han emitido para controlar un tipo de delito económico de gran auge en los últimos años y de mucho peligro para la estabilidad social y política del país es la Ley contra el Delito de Lavado de Activos, creada mediante Decreto número 45-2002, la cual tiene como finalidad la represión y castigo del Delito de Lavado de activos, como forma de delincuencia organizada, fijar medidas precautorias para asegurar la disponibilidad de los bienes, productos o instrumentos de dicho delito, así como la aplicación de las disposiciones contenidas en las convenciones internacionales suscritas y ratificadas por Honduras.

En el ámbito económico esta es una de las leyes que su emisión reviste mayor importancia, siendo la misma de índole eminentemente económica, pues el lavado de activos es legalizar recursos o bienes provenientes de actividades ilícitas, señala 
como fin primordial investigar la procedencia de los recursos económicos generados sin justificar su origen o procedencia, pero además esta ley regula otro tipo de delitos tales como: la asociación ilícita, delito de confabulación, de testaferrato y ekı1elito de infidencia.

Considero que el lavado de activos o blanqueo de capitales o dinero como se le conoce a nivel internacional,cuestiona no solo los cimientos del orden socioeonómiCo, sino incluso, por la importancia que la estabilidad económica tiene en el orden social y público, la propia esencia del sistema democrático.

Sobre esta temática podemos acotar que el término "blanqueo de dinero fue al parecer acuñado en los Estados Unidos de América, durante el decenio de 1920 cuando ciertos grupos de delincuentes callejeros trataron de buscar un origen aparentemente legítimo para el dinero que sus negocios turbios generaban. Por ello, esas bandas criminales adquirieron a veces negocios de servicios pagaderos en metálico, y frecuentemente optaban por comprar lavanderías, servicios de lavados de coches, empresas de expendedores automáticos, etc. La finalidad era mezclar fondos legales e ilegales, y declarar sus ingresos tales como ganancias de su negocio tapadera", típico ejemplo de lo que es el lavado de activos.-

Siendo este delito de ámbito internacional, he investigado algunas consideraciones especiales que sobre el mismo se ha obtenido, tal es el caso que según la Directiva del Consejo de las Comunidades Europeas del diez de junio de mil novecientos noventa y uno, la lucha contra el blanqueo de dinero, se fundamenta en los siguientes principios:

1. El blanqueo de capitales debe combatirse principalmente con medidas de carácter penal en el marco de la Cooperación Internacional entre autoridades judiciales y policiales, sin olvidar que en esta estrategia el sistema financiero puede desempeñar una función sumamente eficaz.

2. La utilización de las entidades de crédito y de las instituciones financieras para el blanqueo del producto de actividades delictivas puede poner seriamente en peligro tanto la solidez y estabilidad de la entidad o institución en cuestión, como la credibilidad del sistema financiero en su conjunto, ocasionando con ello la pérdida de confianza del público. 
3. El blanqueo de capitales se efectúa,en general, en un contexto internacional que permite encubrir mas fácilmente el origen delictivo de los fondos por lo que las medidas adoptadas exclusivamente a escala nacional, sin tener en cuenta la coordinación y cooperación internacional, producción de efectos muy limitados.

El informe del Grupo de Acción Financiero Internacional (GAFI), aprobado en 1996, reconoce que las dimensiones actuales del blanqueo de capitales "son de muy difícil cuantificación y que las fuentes principales de los fondos de origen ilícito son:

a) El narcotráfico (que sigue siendo la fuente principal)

b) Los delitos financieros (estafas, fraudes bancarios, desfalcos, malversaciones, fraudes con tarjetas de crédito, fraudes sobre inversiones)

c) El contrabando

d) El crimen organizado (involucrado en una extensa y amplia gama de actividades criminales)"

En el plano internacional, Honduras suscribió el Convenio de Palermo (Italia), en el cual se establecen nuevas figuras delictivas como el lavado de activos.- Este delito ahora es investigado por la Fiscalía Especial contra el Crimen Organizado y existe la Oficina de Bienes Incautados del Ministerio Público, la cual ha incautado y congelado millones de dólares que están siendo investigados su procedencia, como producto del empeño que han puesto las instituciones investigadoras para combatir ese ilícito.

De igual manera, se ha constituido una Comisión Interinstitucional para investigar e incautar los activos de las personas naturales y jurídicas producto de la quiebra de bancos, puestos de bolsas y financieras, la misma ha sido casi nula su función y está conformada por el Poder Judicial, Tribunal Superior de Cuentas, Procuraduría General de la República, Fiscalía General de la República, Comisión Nacional de Bancos y Seguros y el Congreso Nacional, siendo todas estas instituciones las encargadas de la prevención, control, legislación, aplicación de penas y todo lo relacionado con los delitos de índole económico y financiero.

Es oportuno mencionar que los grandes volúmenes de dinero lavado, los fraudes, las malversaciones que se mueven y crecen de año en año, son una evidencia de que ni los gobiernos, ni las propias instituciones tienen la voluntad ni el interés en erradicar prácticas que les producen importantes beneficios, a pesar de declaraciones, leyes, informes y regulaciones para que las autoridades supervisoras exijan su riguroso cumplimento.- 
El delito financiero sigue evolucionando con rapidez. Las organizaciones criminales internacionales intentan operaciones cada vez más complejas, mientras el desarrollo acelerado de la informática, con el uso de las redes de comunicación electrónica de bancos o compañías, permite que cotidianamente se muevan en tiempo real miles de millones de dólares en transacciones internacionales; en este momento se ejecutan operaciones fraudulentas con bajos niveles de supervisión.-

Se considera que el delito financiero va a continuar representando una amenaza para el sistema financiero internacional, en especial el lavado de dinero, y no es fácil encontrar soluciones prácticas para combatirlo.-

Finalmente sobre este apartado,y por ser este tipo de ilícitos de dimensión internacional, en el seno de las Naciones Unidas en el año dos mil dos, se aprobó la Convención de las Naciones Unidas Contra la Delincuencia Organizada Internacional, la cual tiene como propósito promover la cooperación para prevenir y combatir más eficazmente la delincuencia organizada transnacional, ejecutada por un "grupo delictivo organizado", lo que lo define "como un grupo estructurado de tres o más personas que exista durante cierto tiempo y que actúe concertadamente con el propósito de cometer uno o más delitos graves o delitos tipificados con arreglo a la presente convención, con miras de obtener, directa o indirectamente, un beneficio económico u otro beneficio de orden material."

\section{CONCLUSIONES}

- En el país y en el mundo en general, en los últimos años se ha incrementado la violencia, esto debido a la proliferación de elementos disociadores como las maras, la crisis económica y otros, a consecuencia de ello y para frenar sus estragos, se ha tenido la necesidad de crear y reformar leyes más fuertes que condenan con dureza a los delincuentes.- Pero como ya mencionamos en el presente trabajo, los daños más fuertes ocasionados a las sociedades son los causadas por la comisión de los delitos de índole económico y financiero, agravado esto con la existencia de un vacío de nuestro derecho positivo para la condena con ejemplares castigos a los culpables de la comisión de los mismos.

- En una nación en donde es síntoma de inteligencia el enriquecerse con el esfuerzo ajeno, los órganos operadores de justicia deben comenzar a tomar en cuenta y a 
fijarse en estos super-hombres, que sobreviven gracias a la tibieza de nuestras leyes y a la falta de atención que su actividad provoca.

- Las medidas para hacer más eficaz la prevención y represión de las actividades económicas y financieras sancionadas como delitos, son estudiados y recomendados en reuniones de expertos y en conferencias internacionales: Ellas recomiendan la adecuación de la legislación nacional (creación de tribunales penales económicos), ampliación de las facultades de investigación de fiscales y jueces instructores, estricta separación entre los bancos financieros y bancos comerciales, eliminación del secreto bancario y elaboración y aplicación de nuevas normas internacionales y extensión de la cooperación internacional (intercambio de información, extradición de delincuentes, tratados de Inter. Ayuda judicial, etc) la clave del éxito de tales medidas es fundamentalmente política: La democratización del Estado en los niveles y la total transparencia y el control popular del ejercicio de la función pública.

- En el ámbito nacional, considero que después de ser de público conocimiento el fuerte impacto económico que en Honduras se ha presentado en perjuicio de la sociedad en general, a consecuencia de la comisión de delitos económicos y financieros y siendo increíble que en Honduras a más de veinte años de la existencia del Ministerio Público, ningún delincuente de "Cuello Blanco" está en la cárcel por delitos financieros y corrupción; lo que contribuye a ser considerado uno de los países más corruptos de América Latina; es necesario tomar medidas urgentes para frenar este tipo de ilícitos.

\section{RECOMENDACIONES}

- Revisión del marco jurídico que regula el sistema financiero para modificarlo y adecuarlo a las circunstancias actuales y crear nuevas leyes que den paso a reformas y penas más duras y estrictas para el sistema financiero nacional y que a la vez contengan reformas penales, legales e institucionales para que no se sigan cometiendo este tipo de delitos y para simplificar la detección y facilitar la persecución y ejercicio de la acción penal en el caso de éstos ilícitos.

- En las instituciones gubernamentales y empresas e instituciones financieras se deben endurecer las sanciones contra aquellos encontrados culpables de fraudes, para ello 
se debe exigir que los funcionarios ejecutivos de más alto rango, así como los principales empleados financieros juren - con posibles castigos en caso de mentir que sus reportes y estados son correctos.

- En las Instituciones bancarias, financieras, cooperativas y otras afines se debe reglamentar para evitar que las empresas concedan préstamos personales a sus más altos ejecutivos, práctica generalizada en el mundo de los negocios de todos los países, como lo es también la opción para la compra de acciones a precios menores que los del mercado.

- Se debe mejorar el funcionamiento de entidades importantes para el combate de la delincuencia, como el Poder Judicial, el Ministerio Público, la Policía, el Sistema Penitenciario, los entes Contralores, de igual manera se debe fortalecer su presupuesto.

- En vista que el nuevo Código Procesal Penal es muy garantista, se deben plantear nuevas reformas a fin de poder penalizar con mayor dureza a los responsables de la comisión de ilícitos de esta naturaleza.

- Finalmente junto a la organización jurídica del Estado debe ser suficientemente garantizado su ordenamiento económico y financiero.- De allí surge la razón esencial de una particular y vigorosa protección de la economía y finanzas dentro del campo penal.- De no tomarse los correctivos necesarios para parar este tipo de ilícitos, seguiremos haciendo honor a la impunidad y premiando al delincuente de cuello blanco y castigando a quienes honestamente se ganan la vida, en procura de un futuro mejor.

\section{BIBLIOGRAFÍA}

- $\quad$ Bajo Fernández, Miguel.- Derecho Penal Económico Aplicado a la Actividad Empresarial .- Ed. Civitas, Madrid, 1978.

- Cruz Castro, Fernando.- "Discriminación e Ineficiencia en la persecución del Delito Económico". La Inevitable Perversión del Sistema Penal. 2000.

- Hablemos Claro Financiera .- Edición Septiembre, Octubre 2002 y Enero 2003. 
- Derecho Penal Económico - Manual de Formación Continuada.- Consejo General del Poder Judicial - Madrid 2001.

- Herrero Herrero, Cesar.- Los Delitos Económicos, Perspectiva Jurídica y Criminológica, Ministerio del Interior, Secretaría General Técnica, Madrid.1998.

- Martos Núñez, Juan Antonio, Derecho Penal Económico. Editorial Montecorvo, S.A., Madrid, 1987.

- Miranda Gallino, Rafael.- Delitos contra el orden económico.,- Editorial Pannedille 1970.

- Molinas, Fernando Horacio.- Delitos de Cuello Blanco en la Argentina 1989.

- Pérez, Luis Carlos, Tratado de Derecho Penal, parte especial.- Editorial Temis. T.IV. 1985.

- Quintero Hernández, Hernando.- Los Delitos en el Estatuto Orgánico del Sistema Financiero.

- Revista CCC Delito Financiero Internacional. 2000.

- Revista Summa.- Tina Rosemberg.- Edición octubre 2002.

- Revista de la Unidad Técnica de Reforma Penal.- Justicia Penal, Poder Judicial Honduras, Enero 2002.

- Romero Soto, Luis Enrique. Los Delitos Contra el Orden Económico-Social desde el punto de vista del derecho Comparado, publicado en "Revista Cambio Jurídico". Universidad de Los Andes. Cijus.- 1888. 